\title{
EXPLORING THE POSSIBILITIES OF SUSTAINABLE CHINESE CEMETERY IN URBAN AREA
}

\author{
Zuraini Denan ${ }^{1 *}$ and Sum Wen Yun ${ }^{2}$ \\ ${ }^{1}$ Assist. Prof. Dr., Department of Architecture, Kulliyyah of Architecture and Environmental Design, \\ International Islamic University Malaysia, Malaysia, dzuraini@iium.edu.my \\ ²DN8 Studio, Kuala Lumpur, sumwenyun@gmail.com \\ ${ }^{*}$ Corresponding author
}

\begin{abstract}
In urban cities space for the living is often hard to find, not to mention the dead. In many major urban municipalities, the older cemeteries which were initially considered to be large often run out of space for new burials and vacant land is scarce to extend for cemetery purposes or to develop as new cemeteries. Rapid urbanization in towns and cities has led to a challenge for suitable location. A liveable city must not only care for the wellbeing of the living, but both the living and the dead. With a growing population, the issue should not be taken lightly as it could become a potential threat to urban area in accommodating sufficient burial spaces in the near future. Chinese people do not have a unified religion, therefore, the traditional view of funeral and funeral customs are based on the combined influences of three religions, Order of Confucianism, Natural Law of Taoism and Reincarnation of Buddhism. Death can be comprehended as reincarnation, entering an eternal wonderland, or enter to an unknown world. People refuse to accept and admit death, therefore any religion or knowledge that could help and conquer the contradiction of life and death will be naturally adopted. The problem is whether the existing burial ground in the city can cater for future needs are still questionable. The issue is studied in planning perspective, institutional perspective, environmental perspective, socio-cultural perspective and religion perspective. The aim of the research is to rethink death as a whole in term of religions, cultures, rituals, traditions, practices, perception and value to re-create a meaningful, ecological and sustainable alternative for the care of the deceased and reconnect the living and the dead with nature. It is recommended that future Chinese burial ground to be more multifunctional in order to maintain its sustainability. Ash scattered and ground burial is the most preferred burial methods, while columbarium is becoming more common in Malaysia. Combination of varies preferred methods of burial can help to reduce sole dependent on ground burial where land in the city has becoming scarce and expensive.
\end{abstract}

Keywords: Sustainable, Urban cemetery, Chinese cemetery, Chinese

\section{INTRODUCTION}

Burial is the final resting place of deceased, which is significance and importance for the living and dead. Ethically and customarily, the burial system is attached to the permanence of the burial site and the preservation of the burial land. The investigation of the burial impact is a significant aspect of sustainable development. For whatever reason, death-related problems have not been discussed. The adequacy of cemetery planning is therefore an unregulated problem that is not responsive to changes in society. (Noor 
Shafiqah, Noralfishah \& Mustaffa 2014). This attitude toward it is irresponsible and dangerous given the evidence that documents increasingly aged population in opposition to diminishing burial capacity. Negative associations to cemeteries and their planning are fed by irresponsible media reporting due to general public perception of death as taboo subjects. Because of that, the general public underestimated the importance body disposal and memorialization functions which served by cemeteries and concentrate on the adverse characteristics of the cemetery instead.

This adverse restriction must be addressed and appropriate planning for cemeteries advocated as a challenge for government and municipal planners. In order to do this, people must be convinced that cemeteries are worthy locations and that their historical, multicultural and multifunctional features are highly important. Cemetery carries cultural and historic significance resulting it to be the last place to be replaced or remove. Planning for cemeteries should include cultural, economic and environmental views. It has an intimate connection to numerous researches such as history, sociology, psychology, legislation, economics, ecology and urban development. On the preparation of the cemetery, hardly any academic research is available. Spatial planning should be carried out in order to provide adequate land for cemetery growth. Space planning is the task to compromise the capability of the land and the desire of the people. (Noor Shafiqah, Noralfishah \& Mustaffa 2014). Considerations on numerous problems such as strategies, the economy, the environment, social demands and others should be evaluated in order to make better decisions about potential growth.

\section{ISSUES AND PROBLEMS}

In the last two centuries, worldwide cemeteries have run out of feasible burial spaces. With limited space, come cost surges and increases. A number of countries all over the world are currently facing the ultimate question: what do we do when we run out of cemetery space? These situations are already addressed in countries like Hong Kong and China. The originally creation and extensive use of cemeteries was not intended in a sustainable future during the Industrial Revolution. Nobody was thinking about wondering what would occur if space have been scarce. In some places around the world, cemeteries are expected to be entirely inhabitable and run out over the next twenty years. Although many attempts were made, but the solutions are not solving the problems sustainably: in terms of environment, social and economy.

\section{AIM AND OBJECTIVES}

The study attempts to investigate possibilities of alternative burial method in urban area. In order to achieve the main aim, the investigation outlines objectives of the preliminary study. The objectives are 1) observe and analyse the sustainable development planning in Chinese cemetery and 2) to identify Chinese people perception on Chinese cemetery and sustainability of urban cemetery.

\section{LITERATURE REVIEW}

Literature review gives an overview of the cemetery planning. It discusses the issues need to concern in cemetery planning from institutional, environmental, and social-cultural perspectives.

\subsection{Planning Perspectives}

Countries with land limitations for current cemeteries or difficulties in locating new suitable areas for cemetery planning as it must evaluate all the human remains disposal system and all the parameters associated in the decomposition of bodies (Santarsiero et al, 2000). It is a very challenging issue to identify achievable alternatives because they require both technical parameters and a different way of considering the burial. Cemetery planning is evaluated from various perspectives to get a thorough notion of this ever overlooked and almost undeveloped field in urban planning. Alfe and Reza pointed out, the problem of burial ground shortages which reported intermittently in the local newspaper is an immediate problem in Kuala Lumpur (Alfe \& Reza, 2012).

\subsection{Institutional Perspective}

Many of the cultural traditions that used to constitute part of our community and family have been institutionalized and commercialized today, unlike in old times when the funeral field was extensive or entirely determined by customs or values. "Just as we have allowed the medical profession to institutionalise what is a natural experience at birth, we have allowed the funeral industry to commercialise a natural experience at death." (Marika, 1996)

\subsection{Environmental Perspective}


There are several environmental issues relating to cemetery and they can be categorized into two categories which are physical aspect and ecological aspect. Physical aspect mainly includes primarily cemetery physical features linked to balanced running while ecological aspect mainly refer to environmental factor such as contaminations. (Zhang 2004).

Traditionally, the demand to physical characters on land from cemetery construction is much less causticity compared with those for the living. When comes to the modern trend of cemetery business and services, it has become a necessity of having a complete cemetery building with facilities and improvement. Furthermore, the remembrance process allows family member to memorialize their loved one by preserving the remains, so the cemetery system is attached to the perpetuity of the sepulchre and the preservation of the coffin and the burial site. In this regard, certain required steps in housing of the living should also be taken. (Zhang, 2004)

Religious, social and health reasons all played a crucial role in shaping the cemetery landscapes of the modern society. It is difficult to ignore the apparent fact that traditional cemeteries not only occupy a lot of open land but also have significant negative effects on the environment lying beneath the ground (Giovanna C. L. 2017). Studies showed that cemeteries which are in poor conditions present a potential threat that groundwater contamination is at least as high as standard waste disposal sites (Fisher, 1994). For many years, polluted groundwater on the site and environment of long-standing and spontaneous cemeteries has been considered one of people and society's most pressing concerns.

\subsection{Social-Cultural Perspectives}

Urbanisation is the transformation process that impacts more urban geographic regions. People from rural area move to town and city resulting urban land is shared and becoming scarce whereas population and share of land in rural area decreases. The transformation changes the physical shape of an area and human living experience. Physical urban development changes the nature and landscape as population growth transforms politics and culture. According to Pivo (1996), urbanisation may produce new urban spaces and liveable neighbourhoods or destroy critical environmental features and important cultural resources. Urbanisation rates and patterns give public attention to issues associated with development and the adverse environmental impact. Salisbury (2002) stated death is a transitional stage with loss and adaptation. Death combines the transformation and changes of community balance, physical body and social relations. In different periods of grief the cemetery must fulfill the requirements of the bereaved (Salisbury. 2002). In a physical and psychological context, the cemetery is an essential component of the bigger society.

\section{RESEARCH METHODOLOGY}

The research will consist of 4 main methods: literature review, case study, comparative study and questionnaire survey. Literature review will be based on various form books, journal and newspaper. Two case studies are selected and on site observation is done to provide reliability and authenticity to the research.

\subsection{Observation}

Choa Chu Kang Chinese Cemetery, Singapore and Kwong Tong Chinese Cemetery Seputeh, Kuala lumpur are selected as main case studies to have better understanding to the relevant historical site as well as the existing theory that could explains the past design discipline and provide a good foundation for the future research. The site surveys are planned to be conducted during peak season in the month of Qing Ming to observe the relationship between human flow and spaces. The data is collected in the form of documentation of interview, maps provided by the management and onsite photographs.

\subsection{Questionnaire Surveys}

Questionnaire survey is also conducted on site to visitors who visits the Kwong Tong Chinese cemetery. The goal of the questionnaire survey is to identify Malaysian Chinese people perception on Chinese cemetery and sustainability of urban cemetery. 50 samples of participants are targeted in the survey. Simple random sampling is used to select the respondents randomly from visitors' regardless educational background and social status.

\section{RESULTS AND FINDINGS}

Site visits and observation to Choa Chu Kang Chinese Cemetery Singapore and Kwong Tong Chinese Cemetery Seputeh, Kuala Lumpur were conducted. These two Chinese cemeteries were selected as a focus of case study because of rapid growth development and ever-increasing number of urban population. Visit to both sites, together with questionnaire survey were conducted on peak season during Qing Ming month 
(15March - 14 April 2019) to analyse the cemetery organization during the peak flow. The findings are presented in the Table 2. The goal of the questionnaire survey is to identify Chinese people perception on Chinese cemetery and sustainability of urban cemetery.

Table 2. Result of Case Studies

\begin{tabular}{|l|l|l|}
\hline Field Study & CCKCC & KTC \\
\hline Site Location & $\begin{array}{l}\text { Choa Chu Kang Cemetery } \\
\text { Complex, Singapore }\end{array}$ & Seputeh, KL City Centre \\
\hline $\begin{array}{l}\text { Grave } \\
\text { Arrangement }\end{array}$ & Aligned and paralleled & Loosely arranged \\
\hline Grave Practice & Traditional practice & Traditional practice \\
\hline Topography & Build on depress ground & Built on sloppy ground \\
\hline Vegetation & Mature trees and shrubs & Mature trees and shrubs \\
\hline Softscape & $\begin{array}{l}\text { Grass are planted over the } \\
\text { graves }\end{array}$ & Grass are planted over the graves \\
\hline $\begin{array}{l}\text { Spatial } \\
\text { relationship }\end{array}$ & Internal circulation is limited & Does not direct users to graves \\
\hline People Activities & $\begin{array}{l}\text { Quite a number of people were } \\
\text { seen }\end{array}$ & Quite a number of people were seen \\
\hline Facilities & Basic facilities & Basic facilities \\
\hline $\begin{array}{l}\text { Perimeter } \\
\text { boundary }\end{array}$ & Perimeter buffer planting & Perimeter buffer planting \\
\hline $\begin{array}{l}\text { Degree } \\
\text { openess }\end{array}$ & $\begin{array}{l}\text { Fewer varieties of trees and } \\
\text { shrubs }\end{array}$ & Fewer varieties of trees and shrubs \\
\hline Accessibility & Car park and bus stop available & $\begin{array}{l}\text { Central car park and bus stop } \\
\text { unavailable }\end{array}$ \\
\hline Grave's spatiality & Adequate for ritual practices & Adequate for ritual practices \\
\hline Hardscape & Moderate decorative elements & Moderate decorative elements \\
\hline & & \\
\hline
\end{tabular}

For the purpose of analysing the data and explaining the findings, each 14 elements have been identified which are relevant to the research evaluation criteria by Scheer \& Scheer (Brenda S and Davis S, 2002) have been categorized under 5 characteristics of sustainable development as shown in table below.

Table 3. The Characteristics of Sustainable Development

\begin{tabular}{|l|l|}
\hline Characteristics Of Sustainable Development & Checklist Items \\
\hline Compactness & $\begin{array}{l}\text { Site Location, Grave Arrangement, Grave } \\
\text { Practices }\end{array}$ \\
\hline Conservation & Topography, Vegetation, Softscape (Graves) \\
\hline Integration & Spatial Relationship, Activities, Facilities \\
\hline Provision Of Open Space & $\begin{array}{l}\text { Perimeter Boundary, Degree Of Openness, } \\
\text { Accessibility }\end{array}$ \\
\hline Encouragement Of Moderate Parcel Size & Grave Spatiality, Hardscape (Graves) \\
\hline
\end{tabular}

Table 4. Comparison between the 2 Case Studies 


\begin{tabular}{|l|l|l|}
\hline Characteristics Of Sustainable Development & CCKCC & KTCC \\
\hline Compactness & $\checkmark$ & X \\
\hline Conservation & $\checkmark$ & $\checkmark$ \\
\hline Integration & $\checkmark$ & X \\
\hline Provision of Open Space & $\checkmark$ & $\checkmark$ \\
\hline Encouragement of Moderate Parcel Size & X & $\checkmark$ \\
\hline
\end{tabular}

\subsection{Compactness}

Both Cemeteries are being isolated from their surrounding context. Although Kwong Tong Cemetery is located in city centre, but there is limited link between cemetery to surrounding spaces. Conventional planning methods for burial space have caused cemeteries isolated from the neighbouring context physically and visually. With the new genre of urban cemetery like Choa Chu Kang Cemetery, the inclusiveness of cemetery as part of Public Park and green network is gradually taking place. Grave arrangement of both cemeteries is totally contrast as Singapore is facing land scarcity in the past few decades and the planning of grave is carefully done to minimize the impact poor planning. Small and narrow pathway at the graves giving visitors hard time to walk through and way finding is poor especially in unplanned arrangement graves like Kwong Tong Cemetery.

\subsection{Conservation}

The conventional practice of planning graves on sloppy hill can be seen on both cemeteries and it is one of the guidelines stated by Department of Town and City Planning/Jabatan Perancangan Bandar dan Desa (JPBD). It is common to find shady trees around Chinese cemetery. This creates a rich biodiversity within city ecosystem. Park like ambience can be achieved with right design approach and could be opened for public as recreational space to serve multifunctional purposes. Plants can be seen over the graves in both cemeteries. Excessive shrubs might cause visual barrier and unforeseen danger of insect as growth rate of these plants are relatively fast. Maintenance should be regularly imposed. Normally during festive season like Qing Ming month, shrubs and grass will be trimmed for the ease of visiting or tomb sweeping.

\subsection{Integration}

In term of spatial relationship within cemeteries, Choa Chu Kang cemetery appears to have clearer way finding to grave but pathway is very narrow and encroachment will happen when passing through other graves. Cemetery will be crowded during tomb sweeping month, ghost month, Chinese New Year and date of the death. Apart from that, human activity is minimal despite of regular cleaning routine of maintenance workers. Facilities provided on both cemeteries are basic amenities. Facilities like crematorium or mourning parlor is within the compound but in different building complex.

\subsection{Provide Open Space}

The Kwong Tong Cemetery is surrounded by perimeter fences to ensure the security of the site. Apart from physical access, visually it is still permeable to allow visual interaction between space outside and inside. Accessibility can enhance by having more entrances to enhance human interaction with the surrounding context.

\subsection{Encouragement of Moderate Parcel Size}

From the observation, ritual spaces are inadequate and will be disturbed by other visitors who passed through due to planning arrangement. This has caused some adversities among visitors especially during peak season. The ritual spaces is even narrower in new cemetery from the result of module system to minimize the plot size but striking the balance between user experience and graves size is fundamental and it is another subject to investigate. From site study, the design outline in the new cemeteries is more concerned with systematic order of grave plots rather than fulfilling users need. In old cemetery, some lavish over decorated graves can be seen but in new cemetery decorative elements are minimal yet the overall tradition is still preserved.

Questionnaire survey is also conducted on site to visitors who visits the Kwong Tong Chinese cemetery. Simple random sampling method was employed in finding respondent regardless educational background and social status. It was conducted on peak season during Qing Ming month where the anticipation was 
higher compared to other non -festive months. The goal of the questionnaire survey is to identify Chinese people perception on Chinese cemetery and sustainability of urban cemetery.

Table 5. The Summary Frequency of the Questionnaire survey

\begin{tabular}{|l|c|c|}
\hline Questions & $\begin{array}{c}\text { Agree } \\
(\%)\end{array}$ & $\begin{array}{c}\text { Disagree } \\
(\%)\end{array}$ \\
\hline 1. Do you think land scarcity happens in KL ? & 90 & 10 \\
\hline 2. Do you think there is an urban land issue is critical in KL? & 88 & 12 \\
\hline 3. Is cemetery important in urban area ? & 92 & 8 \\
\hline 4. Do you think cemetery in urban area is sustainable ? & 24 & 76 \\
\hline 5. Is cemetery located around your place an issue ? & 42 & 58 \\
\hline 6. Do you think cemetery should serves multi usage such as park ? & 74 & 26 \\
\hline 7. Is cemetery park nearby your living place an issue ? & 72 & 28 \\
\hline 8. Would you go to the urban cemetry? & 70 & 30 \\
\hline 9. Malaysian Chinese prefers burial ground? & 52 & 48 \\
\hline 10. Malaysian Chinese prefers cremation? & 54 & 46 \\
\hline 11. Do you think ground burial costly? & 86 & 14 \\
\hline 12. Do you think cremation costly? & 12 & 88 \\
\hline 13. Do you think urban dweller can afford ground burial in urban area ? & 18 & 82 \\
\hline 14. Do you think cremation is acceptable? & 80 & 20 \\
\hline 15. Do you think cremation park is sustainable ? & 78 & 22 \\
\hline 16. Do you think ash scattering is acceptable ? & 64 & 36 \\
\hline
\end{tabular}

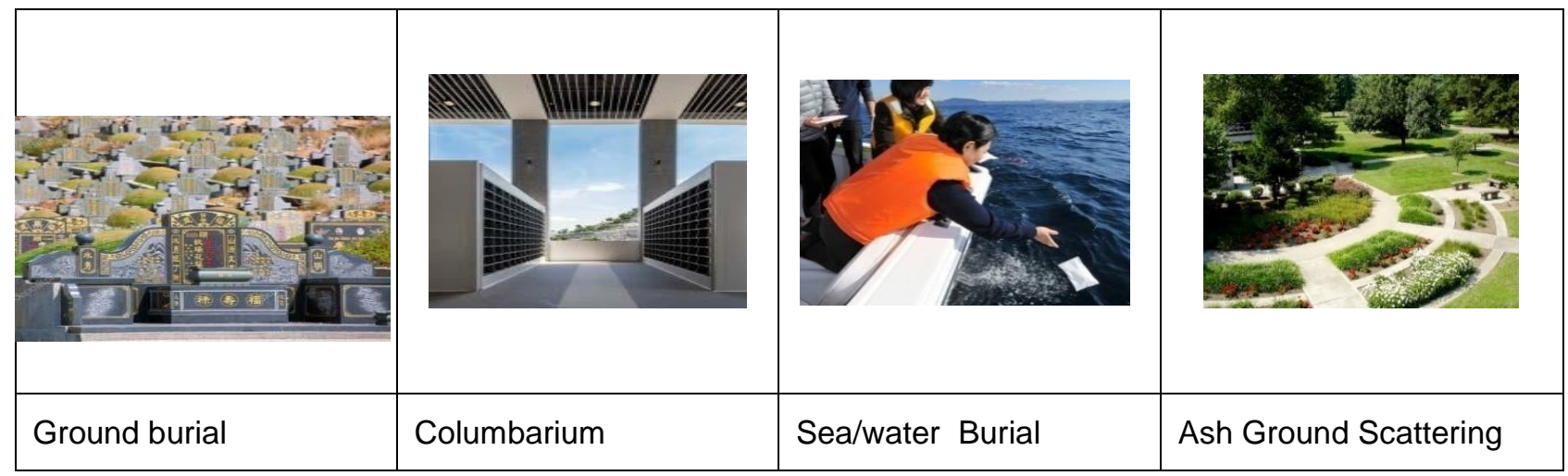

Fig 1. Methods of Burial System

\section{Legend}

Ground Burial Columbarium Sea Burial Esh Scattering

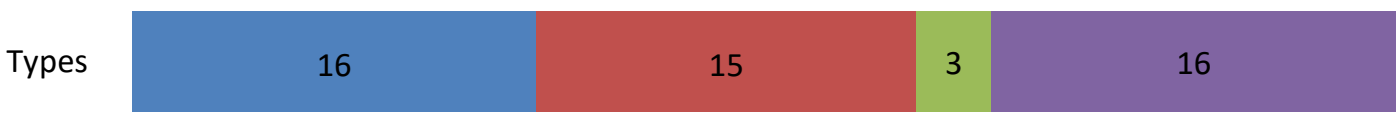

Fig 2. Results of Burial System Preference

Looking at Fig 2. from the overall percentage of burial choices, ash scattering and ground burial are the highest with $32 \%$ each followed by columbarium $30 \%$ and the least favoured sea burial $6 \%$. This reflects that ground burial deemed to be the most popular if the cost is affordable and location is suitable. Although ash scattering is new type of burial method, people can foresee the potential and benefit without changing religion fundamental. Columbarium is the most common form of burial at current time, but in term of sustainability it is still a debatable topic as well as sea burial. 
Land shortage, high land cost, unplanned cemetery layout and management have been major problems faced by community. Demands for both living and burial space became acute. Urban cemetery getting full with no room on their border for expansion, thus finding a solution to these problems is a vital mission. Burial is to satisfy the Chinese desire to preserve their traditions as well as to maintain a green and healthy environment. It is clear that current cemeteries contribute significantly to biodiversity in the town and also Chinese community as it preserves the tradition and culture.

From the perception result, the cremation trend is rising and people are aware of the long unsolved issues including land and environmental issues. Ash scattering is getting acceptable by Chinese community especially in Singapore due to the drastic land shortage condition. These findings are important in achieving the research objective and answering to research questions. Apart from that, these findings support the notion of Cremation Park as a sustainable approach in designing or planning urban cemetery.

\section{CONCLUSION}

Going through the study as a whole, it can be summarized that the planning of cemetery land can be oriented towards multifunctional space to optimize the land use especially in urban area. Malaysian should be allowed to use urban cemeteries as recreational area. With this, the surrounding natural view and the public's negative perception towards cemetery can be eradicated. Indirectly, a positive outlook on burial land will increase and the adjacent area is also improved accordingly.

The cemetery discourse has given insight into environmental ethics, particularly those that are derived from the notion of nature and human unity and harmony and the advancement of a green culture. Cemeteries in the modern era acquire a new significance that integrates an old practice according to the more enlightened perspective of the surroundings. Likewise, Chinese cemeteries have proved how Chinese traditional philosophy can survive and adapt to the call for a healthy setting as Chinese are able to adapt to other cultures without losing their uniqueness. In brief, the land dedicated to the burial of the deceased can at the same time be conserved as a safe and green setting to meet Chinese traditions. In fact, the demands of burial and the preservation of the environment are not contradictory but compatible with the concept of unity and human harmony.

\section{REFERENCE LIST}

Noor Shafiqah Binti Mohamad Daud, Noralfishah Binti Sulaiman, Mustaffa bin Anjang Ahmad (2014). "Issues and Challenges in Muslim Cemetery Management (MCM) in Malaysia."

Basmajian, C. \& Coutts, C. (2010). Planning for the Disposal of the Dead. Journal of the American Planning Association, 76(3), pp. 305-317.

Coutts, C., Basmajian, C. \& Chapin, T. (2011), Projecting Landscapes of Death. Landscape and Urban Planning 102 (2011), pp 254-261.

Santarsiero, A., D. Cutilli, et al. (2000). "Environmental and Legislative Aspects Concerning Existing and New Cemetery Planning."

Zhang Dian (2004). "Land for the Dead, Locating Urban Cemeteries, Case study Guilin, China 2004." Marika, J. (1996). City of the Dead

Giovanna C. L. (2017). "A New Paradigm: The Cemetery for the 21th Century."

Fisher, G. J. and L. Croukamp (1993). Ground Water Contamination and its Consequences. resulting from the Indiscriminate Placing of Cemeteries in the Third World Context. Africa Needs Ground Water.

Pivo, G. (1996). "Toward Sustainable Urbanization on Mainstreet Cascadia." Cities 13(5): 339- 354. Mohamed Afla \& Mohamad Reza, (2012). "Sustainability of Urban Cemeteries and the

Transformation of Malay Burial Practices in Kuala Lumpur Metropolitan Region" World Academy of Science, Engineering and Technology International Journal of Humanities and Social Sciences Vol:6, No:11, 2012.

Brenda S. and David S. (2002). Towards a sustainable urban form in Chiang Mai, managing the development of intermediate size cities, (edited by Michael Romanos and Chris Auffrey Kluwer) Academic Publishing. 
